\title{
Impact of a brief intervention programs in clinical practice: Barriers and adaptations.
}

\author{
Impacto de los programas de intervención breves en la práctica clínica: Barreras y adaptaciones
}

\author{
Kalina Isela Martínez Martínez ${ }^{1 *}$, Ana Lucía Jiménez Pérez ${ }^{2}$, Violeta Félix Romero ${ }^{3}$, Silvia Morales \\ Chainé 3
}

\begin{abstract}
Introduction: The present study analyzes the main barriers and adaptations to brief interventions that focus on addictive behavior treatments carried out in clinical settings by 756 health professionals during their adoption process in 350 Primary Attention Units in Mexico. Method: A descriptive cross-sectional study was conducted and consisted in the application of an instrument that explored diverse aspects, such as knowledge about evidence based brief intervention (BI) programs, barriers during the execution, and adaptations of the BI. Results: the main barriers were related to the implementation of sessions and the user's characteristics such as educational level. As a consequence, the main adaptations were related to the increase in the number of sessions, modifying their length and changing the sequence as well as the proposed material in the manuals. Conclusions: We discuss the possibility of systematizing the adaptations made by health professionals in order to evaluate their effectiveness.

\section{Resumen}

Introducción: Este estudio analiza las barreras y adaptaciones realizadas en la práctica por 756 profesionales de la salud a Intervenciones breves para conductas adictivas durante el proceso de transferencia y adopción en 350 Unidades de Atención Primaria de México. Método: Estudio descriptivo transeccional en el cual se aplicó un instrumento que exploró los conocimientos sobre las IB basadas en evidencia, barreras en la implementación y adaptaciones realizadas a las IB. Resultados: las principales barreras son las relacionadas con la impartición de las sesiones y características de los usuarios como el nivel de escolaridad y por tanto, las principales adaptaciones tienen que ver con mayor número de sesiones, cambios en la duración y en el orden de las mismas así como en los materiales que se proponen en los manuales. Conclusión: Se analiza la posibilidad de sistematizar las adaptaciones realizadas por los profesionales de la salud para evaluar su eficacia.
\end{abstract}

\section{Keywords}

transference; health institutions; brief intervention; addictions; quantitative

Palabras Clave

transferencia; instituciones de salud; intervención breve; adicciones; cuantitativo

${ }^{1}$ Departamento de psicología. Universidad Autónoma de Aguascalientes, Aguascalientes, Ags., México.

${ }^{2}$ Facultad de Ciencias Administrativas y Sociales. Universidad Autónoma de Baja california, Ensenada, Baja California., México.

${ }^{3}$ Facultad de psicología. Universidad Nacional Autónoma de México, CDMX, México.

*Corresponding author: kimartin@uaa.mx

Manuscript received 02-05-2018; revised 22-06-2018; accepted 04-07-2018.

\section{Introduction}

Contemporary research suggests transferring innovations to policies and practice is a challenge, not only for programs to treat substance abuse, but for every area of healthcare practice. The preparation for a structural adjustment has been described as a fundamental concept and a central determinant of the process of adopting a technology (Doheny-Farina, 1992; Weiner, 2009).
It has been previously documented that there are various elements that enable the adoption of innovations. The therapists that have a tendency to adopt an innovation much better are those who have more disposition towards change, meaning that they are flexible regarding the adoption of new forms of treatment which complement or substitute for the ones they previously applied. Referring to the features of the innovation itself, they 
are more easily adopted when they are perceived to be simple, compatible to the necessities and demands of the attention, and capable of generating short-term results.

The adoption of brief interventions (BI's) for substance abuse in clinical scenarios is a task that still unfinished due to barriers of diverse nature (MartínezMartínez, Icaza, \& Elena, 2013). A recent qualitative study reported three types of barriers for the adoption of BIs: 1) Institutional barriers related to bureaucratic and institutional demands; 2) Therapist barriers related to the lack of knowledge about the theoretical basis of the interventions; 3) User barriers related to the disparity between the characteristics of the users that request services and those with whom the BI was initially validated (Martínez-Martínez, Trejo, Yolanda, Echeverría San Vicente, \& Medina-Mora, 2016).

One of the first studies completed in Mexico about technology transfer (Horigian et al., 2016), evaluated the willingness to adopt evidence-based practices (EBP) from therapists specializing in substance abuse within the recent Mexican Network of Clinical Trials constituted by seven ambulatory treatment centers. In this paper, the author also analyzed the work characteristics, current practices and frequency of use of technologies for diagnosis and treatment of substance abuse, as well as the attitudes and barriers towards the technology's implementation. The results demonstrated that healthcare personnel are more willing to adopt Cognitive Behavioral Therapy (83.3\%) and that the main barriers identified were not having enough clinic practitioners, the lack of resources to pay highly trained personnel and insufficient psychiatric and medical support (Horigian et al., 2016).

The analysis of the barriers for the adoption of evidencebased programs has allowed a better approach with the institutions and healthcare professionals who work with populations that reported high drug consumption and negative consequences associated with consumption. Nonetheless, beyond these barriers, it is necessary to investigate the solutions proposed to them and the adaptations made to the programs in order to facilitate and optimize the adoption process of evidence-based interventions, such as the case of the Brief Interventions (BI's) disseminated since 2005 in Mexico by the National Council for Addictions (CONADIC, 2008) to 350 primary attention units (UNEME CAPA) of the country. In these centers, BI's are applied regularly by healthcare practitioners to treat drug consumers. Therefore, the objective of the present study was to identify the main barriers and adaptations made to brief intervention programs by healthcare professionals in their practice during the process of adoption of the 350 primary attention units (UNEME CAPAs).

\section{Method}

\subsection{Participants}

The study was conducted with 756 employees of the 350 Primary Care Centers for Addictions, from all entities of the country who agreed to collaborate by using an on-line platform. $75 \%$ of participants were female. The average age was 35 years old $(S D=6.64)$. Data about their professional experience showed that participants had 9 years of clinical practice on average $(S D=5.57)$ and from those years, six in the field of addiction treatment. $83 \%$ worked as therapists in the institution, $11.3 \%$ represented the coordinators and $5.3 \%$ were directors; all were professionals in the field of psychology.

\subsection{Instrument}

The instrument contains 31 dichotomic items and measures aspects such as: a) identity data, b) characteristics of the BI, c) information about the BI, d) knowledge of evidence-based BI's, e) evaluation of BI programs, f) barriers to the implementation of BI's, g) adaptations to BI programs, and h) therapist's perception of IB programs. The instrument was submitted to judge evaluation. Since the instrument was programmed in Moodle, the answers could be exported from a database without displaying any feedback or score to the participants.

\subsection{Procedure}

A descriptive cross-sectional study was conducted, with the objective of characterizing the professionals precisely as well as the barriers they encountered and the adaptations they made to the BI's.

Due to the large number of participants in the study, they were divided in groups of thirty and assigned to an advisor, who was in charge of sending them the information required for logging into the platform and the instructions needed to fill out the questionnaire. Once each participant had a username and a password assigned, they could access the questionnaire, which had the option of being answered in one or, as mentioned before, in various sessions

In addition to sending the information to the participants, the group of advisors was also in charge of logging in to the platform every day during the week that the questionnaire was available, to encourage participation, verify the progress of the participants and respond to any doubts in case they appeared to have them, as well as encouraging participation.

A descriptive analysis was performed with SPSS version 24. To identify the main barriers reported by the therapists for the implementation of BI's, they were classified into six groups:

- Barriers for the application of BI.

- Barriers related to practitioner's training 
- Barriers related to material resources.

- Barriers related to human resources.

- Barriers related to the manuals.

- Barriers related to the users.

From the barriers mentioned above, each participant could select more than one.

The adaptations made by therapists to the treatments were also analyzed, based on these criteria: objective modifications and number and duration of the sessions. Subsequently, the relation between the barriers reported by participants and the number of adaptations they applied to brief intervention programs was analyzed by performing a Pearson correlation coefficient. A cluster analysis was applied to identify the characteristic of the therapists that may affect the application of the programs.

To identify the adaptations made by therapists is a first step towards recognizing the adherence or lack thereof to the BI's, and also to recognize the necessities for interventions identified by the therapists. This work did not measure if these changes modify the effectiveness of the BI's; this will be done in a following research project which will incorporate the most important adaptations in a clinical guide that will allow therapists to make decisions about the type of intervention, an its duration, objectives, etc.

\section{Results}

As a first step, the preferred theoretical approach was analyzed. $73 \%$ reported having a cognitivist-behavioral perspective, followed by those who reported applying a psychodynamic method $(6.2 \%)$ and systemic family therapy $(4.8 \%)$. The rest of the participants classify themselves as using other approaches such as gestalt therapy, humanism and behavioral therapy.

The main barriers reported by the participants were related to the application of the program and the characteristics of the users. Related to these, the difficulties had to do with the amount of time taken to conduct an evaluation of the problem and the number of tasks assigned to the users. In relation to user's barriers, professionals reported: failure to complete their tasks, problems reading and writing (basic aspects of the whole program's application) and issues in arriving to the center. Another barrier found, was that less than $50 \%$ of the professionals received training about intervention programs.

The main barriers related to materials point to the lack of materials and the difficulty of their contents, which proved to be a disadvantage for user comprehension. It is important to mention that therapists also report not applying the treatment completely as a barrier. Figure
1 shows the frequency of the barriers reported by the participants, by each type of barrier.

An aspect related to the lack of completeness of the treatment, are the adaptations done to the programs. Results showed that $25 \%$ of therapists modified the number of pre-established sessions in the program, adding several. $19 \%$ adjusted the duration of each session, which varied depending on institutional conditions or the severity of the problemat faced. A similar percentage made changes to the materials to adapt them to the user's needs. $15.6 \%$ modified the order proposed in the manuals for the application of each session and $13.9 \%$ included different techniques than the ones proposed in the manuals when implementing a BI, some of which generally do not correspond to a cognitivist-behavioral approach. Figure 2 shows the percentages of diverse types of adaptations to the BI's.

Afterwards, the number of barriers reported by the therapists and the amount of adaptations made to the intervention during its application was analyzed and found to have a positive correlation of $.430(p=.000)$.

For the conglomerate analysis, data from 620 participants was considered. These practiced their profession by implementing the treatment, while the rest of the interviewees did not apply BI's due to their positions at the moment of the study.

For the analysis, two groups were formed, with individuals with an average of 5.81 years and 6.96 years of experience respectively in the field of addiction treatment. Even though the difference does not seem significant, Figure 3 shows that the participants from the second group reported a noteworthy increase in number of barriers and also of adaptations made during the implementation of the program.

Finally, other variables were also analyzed, including the theoretical approach used as reference by the therapists in their practice, and their perception of the utility and pertinence of the programs. However, there were no statistically significant differences in these cases.

\section{Discussion}

The present study sought to enable a closer approach with the therapists that implement BI in all the UNEMECAPAs located in the country. A larger sample was used than previous related studies (Martínez-Martínez et al., 2016) with a quantitative design that would allow the identification of barriers and adaptations involved in the adoption of different brief intervention programs. This enables the guidance and decision making that researchers can make towards modifications of the BI, or for the reinforcement of training for therapists or supervision programs.

The main barriers are those related to the implementation of each session and the characteristics of the users, including educational level. Within implementation, the 

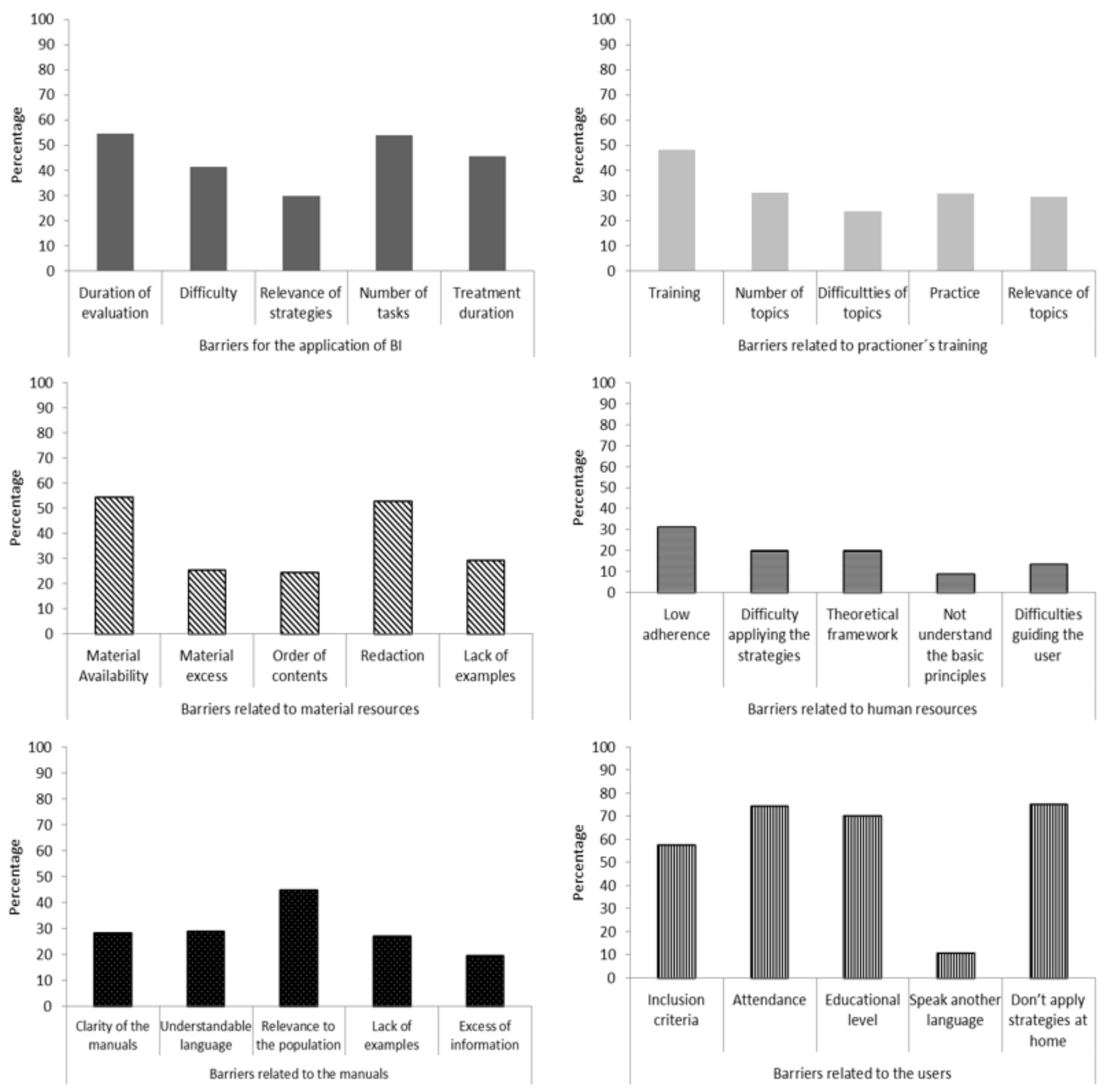

Figure 1. Frecuency and types of the participants' barriers.

Note: Types and subtypes of barriers for the teaching of IBs. (upper left graph), training (upper right graph), material resources (left middle graph), human resources (right middle graph), manuals (lower left graph) and users (lower right graph), in relation to technology transfer, as reported by health professionals.

problems were related to the time it takes to do each evaluation as well as the number of tasks assigned to the users. Barriers related to the characteristics of the users as reported by therapists were that users do not complete the tasks assigned, that their low educational level complicates reading and writing skills and finally, the user's difficulties in going to the center. These replicated results obtained previously (Martínez-Martínez et al., 2016), which showed that the most common barriers mentioned were related to the users not matching the 


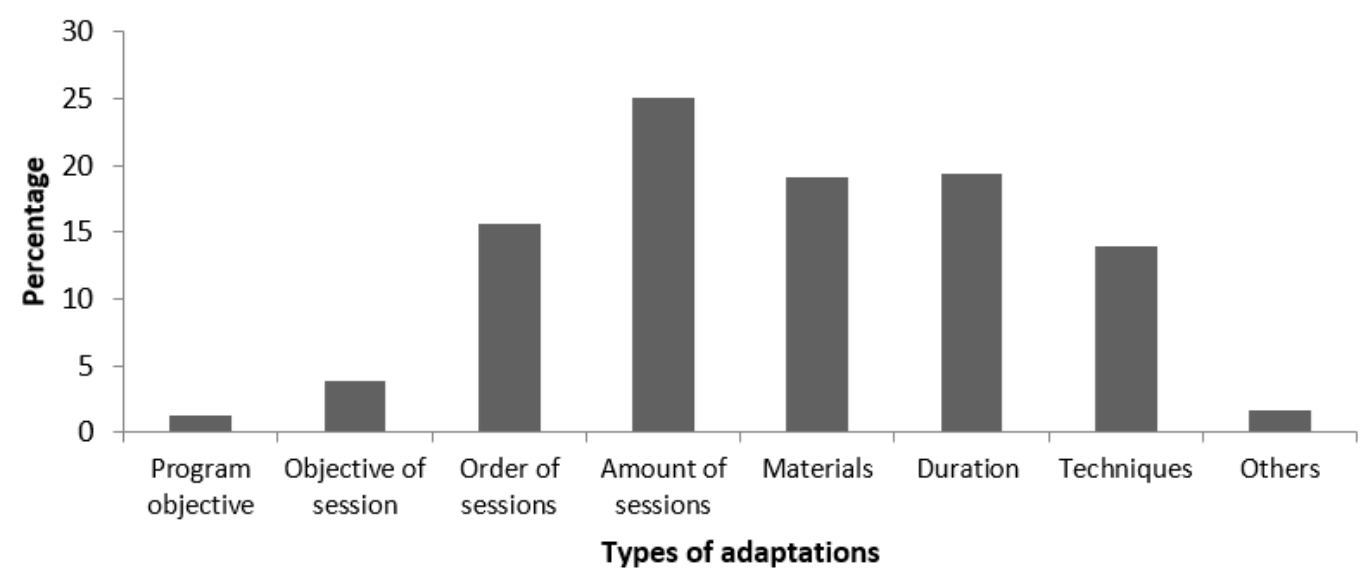

Figure 2. Percentage by type of adaptations made by the total of therapists to the brief intervention programs.

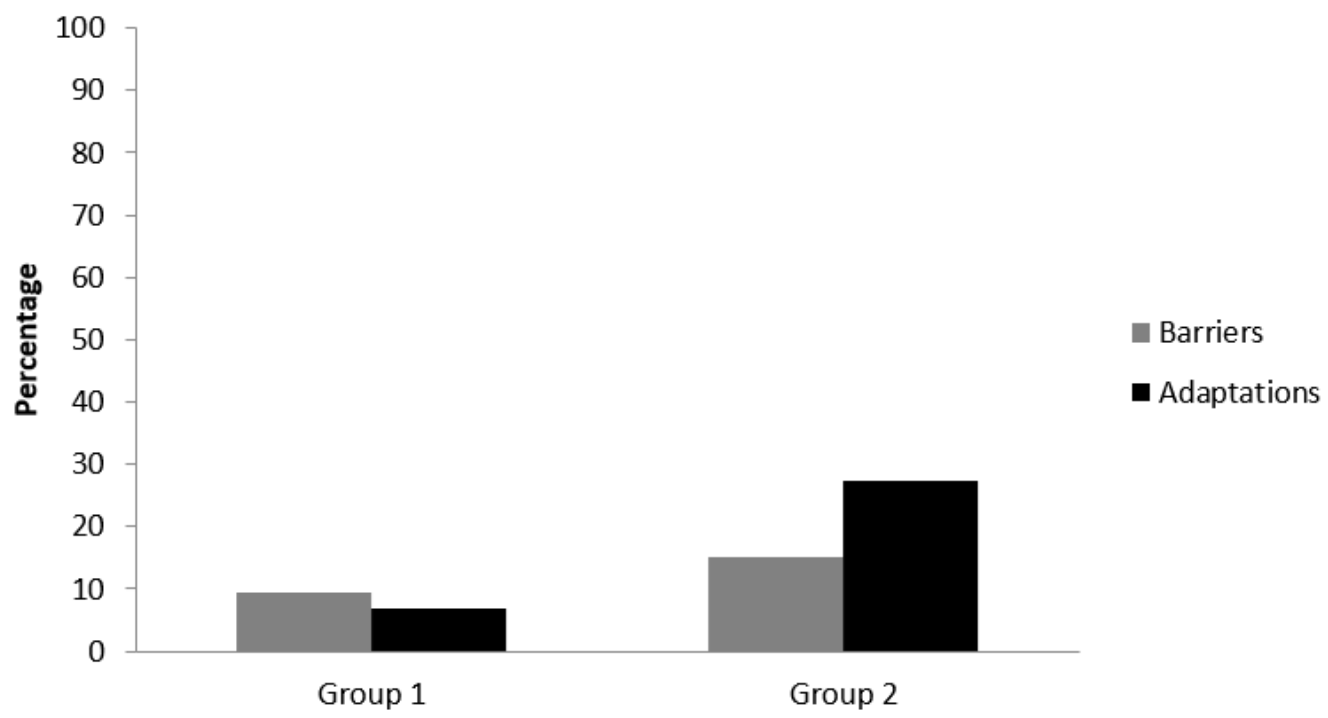

Figure 3. Percentage of barriers and adaptations made by the two groups of professionals identified in the cluster analysis.

inclusion criteria from the evidence-based programs, that their problems were more complex, and finally that due to their educational level they struggled to understand and carry out the tasks of the sessions.

The main adaptations implemented were related to increasing the number of sessions, adjusting each session's duration and modifying the sequence, as well as with the materials that are proposed in the brief intervention manuals. According to the reported information from therapists, it seems that a strict application of the procedure derived from the manuals does not comply with the number of sessions. This may have to do with the difficulty that therapists perceive when following a rigid procedure (Véliz, 2014). Another possible explanation of the adaptations reported by healthcare professionals is related to the natural process of the implementation of these interventions, which derives from decisions made by clinicians before, during and after the application with the aim of properly treating individuals who consume substances.

The most important element to consider to avoid losing the effectiveness of an intervention adaptation is to perform a periodic evaluation that verifies whether the initial treatment is causing a change in consump- 
tion behavior. Otherwise, adjustments in the procedure may occur several times during the intervention process (Weisz, Chu, \& Polo, 2004). In this sense, this research is a first step taken towards the identification of the elements that may influence the adoption and effectiveness of the BI.

The modification of the elements of the treatment through time is a natural and crucial process for multiple reasons, among them the increase in the effectiveness of treatment in achieving abstinence or reducing consumption (Bierman, Nix, Maples, \& Murphy, 2006; Marlowe et al., 2008). As well as reducing costs, this avoids intensive and unnecessary treatment. The decision of when, why and how to implement an adaptation of the intervention must be based on evidence and clear criteria like the severity of the problem, the results obtained after an evaluation and the progress in behavioral change during the treatment (Weisz et al., 2004).

The above highlights the importance of the integrity of the treatment. In this sense, Smith (2013) proposes that focusing the training on the key components for behavioral modification allows the therapists to adopt them with flexibility in different scenarios and with diverse populations without altering their effectiveness. Besides training, another crucial element is supervision, since it identifies the difficulties and advances in implementation and guarantees the adoption of the interventions (Kelly, Hegarty, Barry, Dyer, \& Horgan, 2017; Mihalic, Fagan, \& Argamaso, 2008; Simpson, 2002). Thus, studies that evaluate the efficiency of the treatments should include not only data on successful cases, but also those in which the intervention did not work, which might help the researchers to anticipate the difficulties in implementation.

The modification of treatment elements through time is a natural and crucial process for multiple reasons. Among these it allows an increase in the effectiveness of the treatment, and a reduction in consumption or even abstinence. Another reason is to reduce the use of resources by avoiding unnecessary intensive treatment. The decision of when, how and why to implement an adaptation of an intervention must be based on evidence and clear criteria, such as the severity of the problem, the results obtained after an evaluation, and progress in the behavioral change during treatment (Collins, Murphy, \& Bierman, 2004; Lavori \& Dawson, 2000, 2004; Lavori, Dawson, \& Rush, 2000; Weisz et al., 2004).

The above highlights the importance of treatment integrity. In this repect, Smith (2013) proposes that focusing training on key components for behavioral modification will allow therapists to adopt them with flexibility in different scenarios and populations without altering their effectiveness.

In addition to training, another crucial element is supervision, in such a way that allows the identification of difficulties and successes in implementation and thus guarantee the adoption of the interventions (Mihalic et al., 2008; Simpson, 2002). In this sense, studies regarding the evaluation of efficacy of the treatments should include not only data of successful cases, but also those in which the intervention did not work, which will make it easier for the researcher to anticipate difficulties in the implementation.

The cluster analysis indicates that therapists with more experience reported a greater number of barriers and adaptations. This result is fundamental; if the proposal is to eliminate obstacles to adoption, it must analyze the therapist's training, characteristics and experience, as well as the possible barriers they face and the possible actions that could lead them to positive results. In this sense, feedback and positive reinforcement are essential to increase the adherence of clinicians to the protocols of the program (Andrzejewski, Kirby, Morral, \& Iguchi, 2001). Another course of action addressed to therapists who have more experience in the adoption of BI is that they may act as supervisors and provide feedback in the process of adoption. This may also make therapists more disposed to adopt the interventions.

Consequently, manuals become guidelines for the application of the treatment rather than being perceived as rigid tools that are difficult to follow. This influences beliefs of the therapists regarding the effectiveness of the treatment, since, as previous studies have reported, beliefs and perceptions about a manual's utility and feasibility are key to its subsequent full adoption (Pacheco Trejo \& Martínez Martínez, 2013; Rogers, 2010).

The sequence of critical decisions involves establishing the order in which intervention options will be administered. First, professionals must define the procedures that will be administered and second, consider which changes they will implement if the initial intervention is not successful (McKay, 2009). Possible procedures include different types of interventions, administration, procedure combinations, actions to promote commitment, extent of intervention, and finally intervention adherence.

From a systematic identification of the adaptations made by health professionals and barriers in real life scenarios, a clinical guide will be proposed that integrates an algorithm of decisions based on evidence that leads to the adaptations that professional need to plan and implement an effective intervention.

Although the present research provides information about the barriers and adaptations made by clinics to brief intervention programs, the criteria for the decision making of the therapists as well as the effectiveness of such adaptations are unknown. Therefore, future studies must analyze the criteria which the therapists themselves use to evaluatethe pertinence and efficiency of the modifications they make to the programs.

Finally, considering that the most important barriers are related to treatment users, it is necessary to imple- 
ment the recommendation of the United States Institute of Medicine (McCarty, Greenlick, Lamb, et al., 1998) on conducting controlled clinical trials within the institution's facilities and not only at universities. This to ensure that the programs are clearly developed for clinical populations, considering their characteristics and possible associated problems. At the same time, they recommend conducting a constant and systematic evaluation of the BI programs and their possible adaptations through time in centers for addiction treatment (McCarty et al., 1998).

Therefore, a pending task in these types of studies is to use diverse indicators to measure the adoption of brief intervention programs after more than 10 years of their dissemination and transfer in addiction treatment centers in the country. Although the results of the present study reveal that therapists make modifications to BI, there is no data related to the systematicity with which these modifications are applied nor of their efficiency. A key element for a successful transfer and adoption of an intervention is to maintain the efficacy level in results found in controlled studies.

\section{References}

Andrzejewski, M. E., Kirby, K. C., Morral, A. R., \& Iguchi, M. Y. (2001). Technology transfer through performance management: The effects of graphical feedback and positive reinforcement on drug treatment counselors' behavior. Drug and Alcohol Dependence, 63(2), 179-186.

Bierman, K. L., Nix, R. L., Maples, J. J., \& Murphy, S. A. (2006). Examining clinical judgment in an adaptive intervention design: The fast track program. Journal of Consulting and Clinical Psychology, 74(3), 468.

Collins, L. M., Murphy, S. A., \& Bierman, K. L. (2004). A conceptual framework for adaptive preventive interventions. Prevention Science, 5(3), 185-196.

CONADIC. (2008). Modelo de atención UNEME-CAPA centros de atención primaria en adicciones "Nueva Vida". Centro Nacional para la prevención y el control de las adicciones. México. D.F..

Doheny-Farina, S. (1992). Rhetoric, innovation, technology: Case studies of technical communication in technology transfers. MIT Press.

Horigian, V. E., Espinal, P. S., Alonso, E., Verdeja, R. E., Duan, R., Usaga, I. M., ... Feaster, D. J. (2016). Readiness and barriers to adopt evidence-based practices for substance abuse treatment in México. Salud Mental, 39(2), 77-84.

Kelly, P., Hegarty, J., Barry, J., Dyer, K. R., \& Horgan, A. (2017). A systematic review of the relationship between staff perceptions of organizational readiness to change and the process of innovation adoption in substance misuse treatment programs. Journal of Ssubstance Abuse Treatment, 80, 6-25.

Lavori, P. W., \& Dawson, R. (2000). A design for testing clinical strategies: biased adaptive within-subject randomization. Journal of the Royal Statistical Society: Series A (Statistics in Society), 163(1), 29-38.

Lavori, P. W., \& Dawson, R. (2004). Dynamic treatment regimes: practical design considerations. Clinical Trials, 1(1), 9-20.

Lavori, P. W., Dawson, R., \& Rush, A. J. (2000). Flexible treatment strategies in chronic disease: clinical and research implications. Biological Psychiatry, 48(6), 605-614.

Marlowe, D. B., Festinger, D. S., Arabia, P. L., Dugosh, K. L., Benasutti, K. M., Croft, J. R., \& McKay, J. R. (2008). Adaptive interventions in drug court: A pilot experiment. Criminal Justice Review, 33(3), 343-360.

Martínez-Martínez, K. I., Icaza, M. M., \& Elena, M. (2013). Transferencia tecnológica en el área de adicciones: El programa de intervención breve para adolescentes, retos y perspectivas. Salud Mental, 36(6), 505-512.

Martínez-Martínez, K. I., Trejo, P., Yolanda, A., Echeverría San Vicente, L., \& Medina-Mora, M. E. (2016). Barreras en la transferencia de la tecnología: Un estudio cualitativo de las intervenciones breves y los centros de atención a las adicciones. Salud Mental, 39(5), 257-265.

McCarty, D., Greenlick, M. R., Lamb, S., et al. (1998). Bridging the gap between practice and research: Forging partnerships with community-based drug and alcohol treatment. National Academies Press.

McKay, J. R. (2009). Treating substance use disorders with adaptive continuing care. American Psychological Association.

Mihalic, S. F., Fagan, A. A., \& Argamaso, S. (2008). Implementing the LifeSkills Training drug prevention program: factors related to implementation fidelity. Implementation Science, 3(1), 5.

Pacheco Trejo, A., \& Martínez Martínez, K. (2013). El arte de ser terapeuta.? Qué hace efectiva una intervención en el consumo de drogas? Enseñanza e Investigación en Psicología, 18(1).

Rogers, E. M. (2010). Diffusion of innovations. Simon and Schuster.

Simpson, D. D. (2002). A conceptual framework for transferring research to practice. Journal of Substance Abuse Treatment, 22(4), 171-182.

Smith, T. (2013). What is evidence-based behavior analysis? The Behavior Analyst, 36(1), 7-33.

Véliz, M. (2014). Barreras del terapeuta en el uso de manuales (Unpublished master's thesis). Universidad Autónoma de Aguascalientes. 
Brief intervention: barriers and adaptations (Research Article) - 34/34

Weiner, B. J. (2009). A theory of organizational readiness for change. Implementation Science, 4(1), 67.

Weisz, J. R., Chu, B. C., \& Polo, A. J. (2004). Treatment dissemination and evidence-based practice: Strengthening intervention through clinicianresearcher collaboration. Clinical Psychology: Science and Practice, 11(3), 300-307. 